\title{
COMMUNICATION ACROSS NATIONS
}

These days goods, capital, and labor move freely across borders. During the last forty years international trade has increased by $1500 \%$ as tariffs have fallen from $50 \%$ to less than $5 \%$. That is why multinational companies like Exxon do two-thirds of their business outside the US and components for the new Ford come from fifteen different countries. The management of global companies as well as the management of brands internationally has partly become a cross-cultural issue where communication across nations takes the crucial role on the way to success.

Keywords: Cultural awareness, communication, language, culture, management, multi-nationals.

\section{Introduction}

While thinking of currently happening globalization processes The Economist [1] has identified these key contributors to globalization:

- free movement of capital "at the touch of a button" which is the fuel of investment in all its forms,

- trade liberalization with lowering of trade barriers,

- lowering of shipping costs thanks to the efficiency of containerization, ${ }^{1)}$

- reduction in telecommunications and computing cost. ${ }^{2)}$

Organizations with the resources and expertise to exploit the information on their networks on a worldwide scale will have a key competitive advantage in many industries. Operating in and producing for not only one country, or even one continent, allows a company to reduce costs and benefit from economies of scales.

Some implications of this for managers have been suggested by points raised in a series in the Financial Times [2]. Even in a company that operates within one country, there is often resistance to ideas from outside, the not invented here syndrome; and with subsidiaries in many countries, this becomes more of a problem, because it is compounded by cross-cultural issues and potential misunderstandings. Resistance to the way of doing things elsewhere may be even stronger if the subsidiary was previously a local company taken over by a multinational, perhaps with loss of jobs and loss of sense of security among those that remain. The management of global companies (as well as the management of brands internationally ${ }^{3)}$ ) is partly a cross-cultural issue. Developing international teams of managers working in a multicultural environment has become a challenge.

\section{Managing across cultures}

As the world gets smaller, we need to learn more about each other's values, beliefs, habits and expectations. Culture is, in the famous phrase, the way we do things around here [3]. The "here" in question may be a country, a region, a social class, a company, a university. Clearly, we each live in a set of cultures and subcultures that interlock in complex ways, and, to make a generalization, one of the most dangerous thing is to generalize about them. Stereotypes are, of course, to be handled with caution. The stereotype may represent the middle of a range of different behaviors, it may be at one extreme, or it may just not be true. And there may be more variety in behavior within a culture than between one culture and another.

Neighboring countries or regions, or two companies in the same industry, tend to see themselves as very different to each other, but that difference is hard for the outsider to grasp at first glance. A few years working in one of the two places will make seem more apparent, as one gets "involved" in one of the cultures. One can

\footnotetext{
* Jana Lopusanova

University of Zilina, Faculty of Science, Department of Foreign Languages, Slovakia, E-mail: jana.lopusanova@fpv.uniza.sk

1) The shipping charge for a whole container of goods crossing the Pacific can be as little as $\$ 50$. The transport cost for each "Japanese" TV, probably made in Malaysia or elsewhere, sold in the US or Europe is negligible.

2) The cost of a 3-minute phone call form New York to London in 1930 was $\$ 300$ in today's money. There is more computing power in the average wrist watch today than there was in all world's computers in 1950.

3) A brand like Coca-cola has been around for a long time, and dominates the fizzy market in almost every country, outselling local brands. One exception is Scotland, and their marketing specialists are trying to find out why this is, in an international market that should by now be truly homogenous. Anomalies such as the French preference for top-loading washing machines when the rest of Europe prefers door-loading ones, or the American liking for $4 \mathrm{x} 4$-type vehicles rather than saloon cars, even in cities, could be related to the smallness of French apartments or the cheapness of American petrol. But there have always been cultural "traditions" that are harder to explain. Why do Spanish drink so little tea? Why do Germans eat so many bananas?
} 
also think of promoting the same corporate policy at a global level, fostering diagonal promotions as well as geographical relocation of managers three or four times in their first dozen years which can help a multinational corporation to become global, cultural aware and sensitive.

Here (in no particular order) are some cross-cultural issues, areas where there are variations in behavior across different cultures, and some examples of the ways they relate to the business world: [4]

- Religion: is it expected of people or a matter of individual choice: Does it play a role in business life?

- Roles of men and women: are women often found at the highest levels of business and society?

- Hierarchy: what is the distance between managers and people who work for them?

- Levels of formality in language and behavior: is there an elaborate system of levels of deference in addressing different people?

- Conversation: settings (formal and informal meetings, social situations, etc.) turn-taking, periods of silence, proximity, body language, eye contact, showing emotions, saving face, using first names, role of humor, small talk, etc.

- Dress for different settings and occasions: is the business suit essential?

- The relation of work to private life: are spouses expected to attend certain types of company events? Do business people invite colleagues and contacts to their houses, or is everything done in the office and restaurant? What about working extra hours, giving gifts, exchanging business cards, taking shoes off, etc.

- Time: time scale of the activity/organization, planning the working day/week/year, meals, recreation, holidays, etc. Do meetings start on time? What about the summer break? etc.

One can also ask and answer a question how important the following characteristics might be at a workplace or for doing business in a foreign country? It is possible to think which of them are very, less or not important and which should rather be avoided.

We can think of: [5]

After having a discussion on the above mentioned characteristics one can possibly get a fair picture of its own or foreign culture or company's business behavior within one culture.

Cultural management has become a crucial issue nowadays. Meeting members of other culture can on one side be very helpful in getting practical experience in knowing and understanding new/different culture but, on the other hand, cultures differ which might be the source of misunderstandings. And everyone (not only in business) should be aware of this. Many books on multi/cross-cultural management suggest that the world can be divided into three geographical groups:

North America [1]

Europe, Latin America, Middle East [2]

Japan, China, East Asia [3].

Based on surveys carried out on various intercultural differences we can try to characterize these groups of countries and describe them from these points of view:

- Company values

- Business relationships

- Meetings

- Presentations. [6]

Company values

- Group harmony, long-term relationships, loyalty, company reputation. $[3]^{4)}$

- Trust between individuals, compromise, and personal reputation. People work to live. [2]

- Competition between individuals, achievement, action, risk-taking, directness, informality, innovation. People live to work. [1]

\begin{tabular}{|c|c|c|}
\hline \multirow{2}{*}{\multicolumn{3}{|c|}{ Not important/ to be avoided }} \\
\hline & & \\
\hline - punctuality & $<-\ldots$ & $\ldots . .>$ \\
\hline - physical contact & 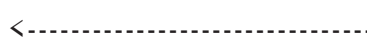 & - \\
\hline - humor & 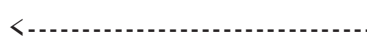 & -............ \\
\hline - giving gifts & 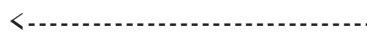 & chos \\
\hline - socializing outside work & $<-1,-1$ & -.......... \\
\hline - physical appearance & 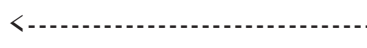 & -........> \\
\hline - small talk & 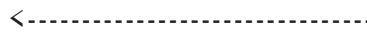 & $-\cdots-.->$ \\
\hline - showing emotions & 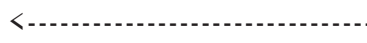 & [-.............> \\
\hline - working extra hours & 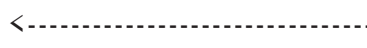 & - \\
\hline - appearing to be busy & 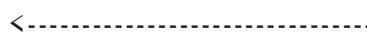 & - \\
\hline - formality between levels in the company's hierarchy & $<-\infty-\infty$ & 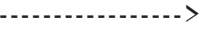 \\
\hline
\end{tabular}

Table 1 Work place characteristics

\footnotetext{
4) Numbers given at the end of the utterances apply to the culture where these standards are common according to the above mentioned division of the world into three geographical groups.
} 
Business relationships

- Friendly and informal, but a continuing personal relationship is not important. Much business is done over the phone. [1]

- Done on a group basis, although relationships based on mutual respect are important. Often there is an older authority figure that rarely appears but has ultimate power. [3]

- Personal relationships are very important. Some time is needed to build trust before business can begin. There is preference for doing business face to face. [2]

\section{Meetings}

- Objective is to gather information. Communication is often "monologue - pause - monologue" rather than dialogue. Arguments are often indirect, and there are no sudden changes of viewpoint in meetings. Decisions are made by group consensus over a long time period. [3]

- Objective is to make a deal or decision. Communication style is direct, factual, informal and at times confrontational. Decisions are based on facts, and are often made instantly in the meeting. [1]

- Objective is to establish relationships, build understanding, clarify, and issue instructions. Communication style depends on national culture. Decisions are made by key individuals, outside the meeting. [2]

\section{Presentations}

- Complicated language may be used to show education. Audience expects formality and a logical structure, but a touch of imagination is also appreciated. May want a more personal "extra" talk afterwards where you tell them the "truth". [2]

- Indirect, conservative language. Audience appreciates a quiet, formal presentation with visual aids and lots of opportunity to ask questions and check understanding. They expect separate handouts, prepared for different people, by job function. [3]
- Direct, simple language. Audience expects jokes, modernity, logic, slogans, informality and a hard sell. Audience may ask questions or interrupt while someone is speaking, and will openly question inconsistent facts. [1]

\section{Communication tools for understanding cultures}

Definitely there are differences in speaking and communication styles and tools among cultures as well. We in this context mean culture not in the sense of literature, music or art but in the sense of system of shared attitudes, beliefs, values or behavior. Culture manifests itself both in patterns of language and thought and in forms of activity and behavior. These patterns have become models for common adaptive acts and styles of expressive behavior which enable people to live in a society within a given geographical environment and at a given state of technical development. Culture as well can be viewed as a communication problem, because it is not constant but it varies. And as cultural variance increases, so do the problems of communication [7].

In When Cultures Collide cross-cultural consultant Richard D Lewis [8] talks about the role of small talk ${ }^{5)}$ in international business. The diagram below shows how long it takes different nationalities to get down to business.

Communications expert Fons Trompenaars [9] in his work Riding the Waves of Culture, shows how different cultures have different discussion styles. The diagram below illustrates his results. The lines represent two speakers and the spaces represent the silences. When lines and spaces overlap it shows that people are speaking at the same time [10].

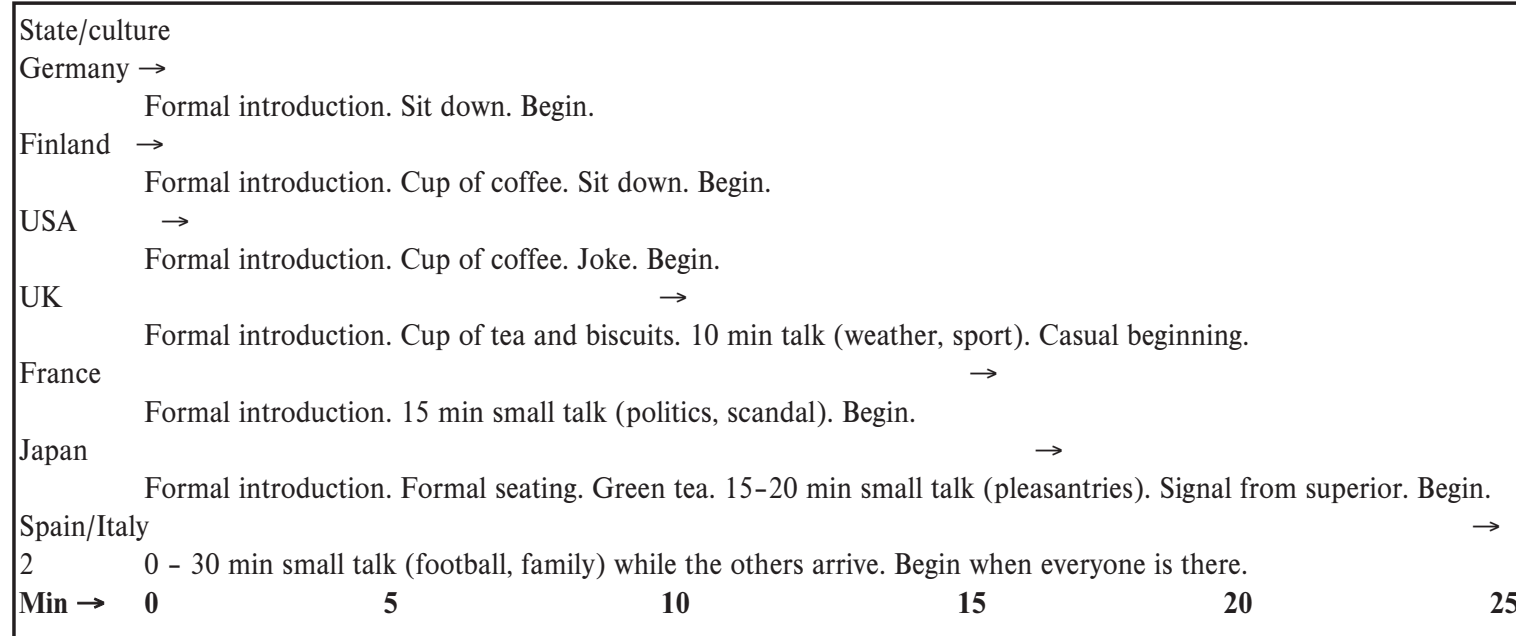

Diagram 1 Small talk

\footnotetext{
${ }^{5)}$ Small talk is a social dialogue held at the beginning of a meeting or a business negotiation, often called chit-chat as well. In different cultures the role of small talk is different.
} 


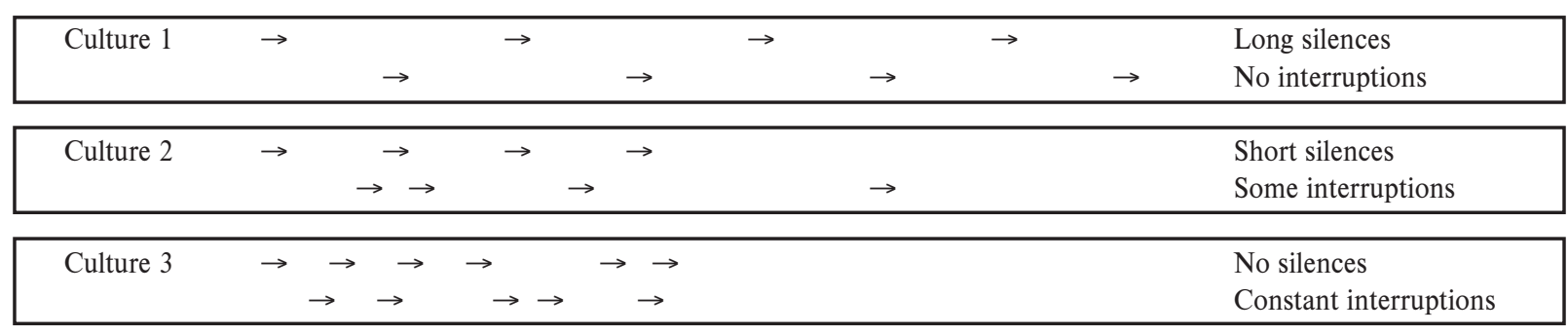

Diagram 2 Discussion style

As the intercultural communication is not yet a part of the language preparation at schools or universities it is becoming a crucial issue what can cause a bigger problem: to be the best at vocabulary, grammar and functions, or to be able to understand cultural differences, be able to greet in an appropriate way, with the correct intonation, handle business cards, respect others and understand that the English language is what we call a bridge for meeting other cultures but at the same time be aware that English is not the only tool that is available. There has been a significant rise in the meaning of the non-verbal communication as well. And this is where we see the future of the foreign language teaching and language preparation going hand in hand with providing practical examples and information from the area of cross-cultural management and economy in the sense of respecting and understanding cultures.

"The most important thing in communication is to hear what isn't being said". That, at least is the opinion of management guru, Peter Drucker, for most of us, hearing what is being said is quite difficult enough. Part of the problem is that languages are spoken at very different speeds. Polynesians belong to some of the world's slowest speakers, converse at a leisure 100 syllabus a minute. The English too take their time at 150 to 200. Germans on the other hand, can often manage a swift 250. French and Spaniards race along at 350 syllables a minute. Surprisingly, the Japanese speak at "almost Spanish" 300 syllables. But that doesn't take account of the long periods of silence they are also famous for. Some of these can last nearly a minute themselves, for in Japan silence is just another form of communication. That's why one should never interrupt it [11]. (Silence together with the speed, rate, intonation, pauses, paralinguistic elements, gestures, posture, distance, saving face phenomenon, etc. all belong to the area of non-verbal communication.)

According to various authors there are tools for understanding cultures. First of all we need to be cultural fluent. Cultural fluency means understanding what culture is, how it works, and the ways culture and communication are intertwined with conflicts.

Even if this may sound simple, it does require some effort. Hall [13] writes in the introduction to his book, The Dance of Life, that we should reorganize our thinking and that only few of us are willing to risk such a radical move. Communication theorists, anthropologists, and others have given us tools to develop our cultural awareness.
In the next part we would like to explore two of them here:

- High and low context cultures

- Cultures based on individualism and cultures based on group harmony.

High-context and Low-context communication refer to the degree to which speakers rely on factors other than explicit speech to convey their messages. This tool was developed by E. T. Hall and it suggests that communication varies according to its degree of field dependence, and can be classified into two categories: highcontext and low-context. Field dependence refers to the degree to which things outside the communication process influence meaning.

E. T. Hall says that humans are confronted by many sensory stimuli. Cultures help in process of screening messages, shaping perceptions and interpretations according to a series of filters. In high-context settings, the screens are designed to let in implied meanings arising from the physical setting, relational cues, and shared understandings. In low-context settings, the screens direct attention more to the literal meanings of words and less to the context.

We have to be aware of the fact that we get involved in both high-context and low-context communication. Sometimes people exactly say what they mean, and mean what they say and leave very few explicit messages, which is an example of low-context communication.

At different times people use nonverbal communication more, do not (want to) say exactly what they mean, use indirect messages which is an example of high-context communication.

When people communicate they are more or less explicit and direct and move between high and low context depending on the relationship, situation, and/or the purpose of communication. In close relationships, when people know one another well, communication can be high context, indirect, hard to understand for an outsider... With new people, our conversation is more direct, explicit and based on words and their exact meaning.

Low- and high-context communication can be used to understand different cultural groups. We distinguish low/er context cultures: are German, Scandinavian, American, English Canadian and high/er context cultures: French Canadian, French, Italian, Spanish, Mexican, Greek, Arab, Chinese, Japanese, Korean. 
Generally said, Western cultures tend to move towards lowcontext starting points, while Eastern and Southern cultures tend to use high-context communication which is why there are so many important differences. In high-context communication settings, it is necessary to pay great attention to nonverbal signals and behavior of others communicators involved. In low-context communication settings directness plays the key role.

"The choice of high-context and low-context as labels has led to unfortunate misunderstandings, since there is an implied ranking in the adjectives. In fact, neither is better or worse than the other. They are simply different. Each has possible pitfalls for cross-cultural communicators. Generally, low-context communicators interacting with high-context communicators should be mindful that

- nonverbal messages and gestures may be as important as what is said;

- status and identity may be communicated nonverbally and require appropriate acknowledgement;

- face-saving and tact may be important, and need to be balanced with the desire to communicate fully and frankly;

- building a good relationship can contribute to effectiveness over time; and

- indirect routes and creative thinking are important alternatives to problem-solving when blocks are encountered.

High-context communicators interacting with low-context communicators should be mindful that

- things can be taken at face value rather than as representative of layers of meaning;

- roles and functions may be decoupled from status and identity;

- efficiency and effectiveness may be served by a sustained focus on tasks;

- direct questions and observations are not necessarily meant to offend, but to clarify and advance shared goals; and

- indirect cues may not be enough to get the other's attention.

If communicators are aware of high-context and low-context communication in their relations, conflicts may be lessened and even prevented.” [14]

Individualism and communitarianism is the second dimension we want to examine because we think it might be another source of a possible conflict and misunderstanding.

In communitarian/collectivist settings children are taught that they are part of a circle of relations. They identify themselves strongly with the group, its norms, values, dependence, and cooperation. Duty, honor, and deference to authority are to be respected. Wherever they may go, their identity being a member of their group goes out in front.

Individualist patterns involve ideas of being on one's own, independent, self-directed, autonomous, it represent someone who is able to make proposals, concessions, and maximize gains in his/her own self-interest. Children and youngsters are praised for their initiative, achievements, and individual leadership. They have a free option concerning their own preferences.
"Individual and communitarian identities are two quite different ways of being in the world. They connect at some point, of course, since all groups are made up of individuals and all individuals find themselves in relationship with various groups. But the starting points are different. To discern the basic difference, ask yourself which is most in the foreground of your life, the welfare, development, security, prosperity, and well-being of yourself and others as individuals, or the shared heritage, ecological resources, traditional stories, and group accomplishments of your people? Generally, those who start with individualism as their beginning tend to be most comfortable with independence, personal achievement, and a competitive conflict style. Those who start with a communal orientation are more focused on social connections, service, and a cooperative conflict style" [15].

According to M. LeBaron one possible way to know and distinguish communitarian or individualist starting points is to listen to their forms of greetings and addresses. "Thomas Morning Owl, a member of the Confederated Umatilla Tribes in Oregon, reports that his response to the question 'Shinnamwa?' (Who are you?) would not be his name, but a description of his father, mother, and tribe, and the place they came from. Morning Owl reflects that individual identities are subsumed into the collective in his culture: "Who preceded you, is who you are." [16].

Representatives of collectivist cultures place less importance on relationships with outsiders, (strangers, casual acquaintances) than individualists. In Japan, attention is focused on maintaining harmony and cohesion with the group. (Compare with a Japanese proverb "None of us is as smart as all of us.") The U.S. American behavior of friendliness towards strangers might be seen inappropriate and too familiar by people from communitarian settings, whereas U.S. Americans find social networks in communitarian settings very difficult to penetrate. And this phenomenon can also be a source of a possible misunderstanding across cultures.

"No matter which starting point seems natural, it is important to keep the entire continuum in mind when trying to understand and address conflict. From each vantage point, it is useful to remember some things:

From an individualist starting point,

- achievement involves individual goal-setting and action;

- I am ultimately accountable to myself and must make decisions I can live with;

- while I consult with others about choices, I am autonomous: a discrete circle; and

- I believe in equality and consider everyone able to make their own personal choices.

From a communitarian starting point,

- maintaining group harmony and cohesion is important, and my decisions should not disrupt that;

- choices are made in consultation with family and authority figures and their input is weighted as heavily, or even more heavily, than mine. I am an overlapping circle amidst other overlapping circles; 
- my decisions reflect on my group and I am accountable to them as a member; and

- I notice hierarchy and accept direction from those of higher status than myself.

With these differences in mind, it is important for individualists to recognize the web of relations encompassing the communitarian party to a conflict, and to act in recognition of those. Similarly, it is helpful for those from communitarian settings to remember that individualists value autonomy and initiative, and to act in ways that respect these preferences" [17].

Furthermore we can distinguish between:

- Linear-active, multi-active and reactive cultures

- Cultures with "monochromic" or "polychromic" attitude towards time

- Cultures with different time-orientation, etc.

G. Hofstede [18] has found five dimensions of culture in his study of national work related values: low vs. high power distance, individualism vs. collectivism, masculinity vs. femininity, low vs. high uncertainty avoidance and long vs. short term orientation.

R. D. Lewis [19], author of many classic works in cross-cultural communication, has significantly broadened the phenomenon of global business and communication. In his work When cultures collide he captures the rising influence of culture and changes throughout regions of the world. Famous for his LMR model he gives leaders and managers as well as teachers practical strategies to embrace differences and help them work successfully across increasingly diverse business cultures.

At this stage we would like to present a few practical examples from a work place [22] and comment on them:
When making business abroad or having negotiations with a member of a different culture at his/her place there might be some of the following situations very likely to happen.

A

You meet a Spanish business colleague you haven't seen for ages who wants to stop and chat, but you're running late for an appointment. Do you stay or do you make your excuses and go?

$\mathrm{B}$

A British salesman is giving you a demonstration of a new office product. He seems to like telling a lot of jokes. Do you join in the joke-telling or wait until he gets to the point?

$\mathrm{C}$

You are having a pre-negotiation coffee at a potential client's headquarters in Bonn. Do you mingle with the opposing team or stick with your own people?

D

Your new American boss organizes a weekend barbecue. You find yourself amongst a lot of people you've never met. Do you join in the fun or slip away quietly?

$\mathrm{E}$

A Finnish colleague invites you to conduct the final stages of an important meeting in the sauna. Do you accept or politely decline?

Here we present some comments on the issues above [23]:

A

Business people from Latin and Arab countries tent to have a more flexible, "polychromic" attitude to time than their "monochromic" North American and North European counterparts - for them time is money. Their "high-context" culture also places greater emphasis on personal relationships than "low-context" Northerners do. The message for us is not to be too busy for Brazilians or Italians and don't mess up Americans' tight schedules.

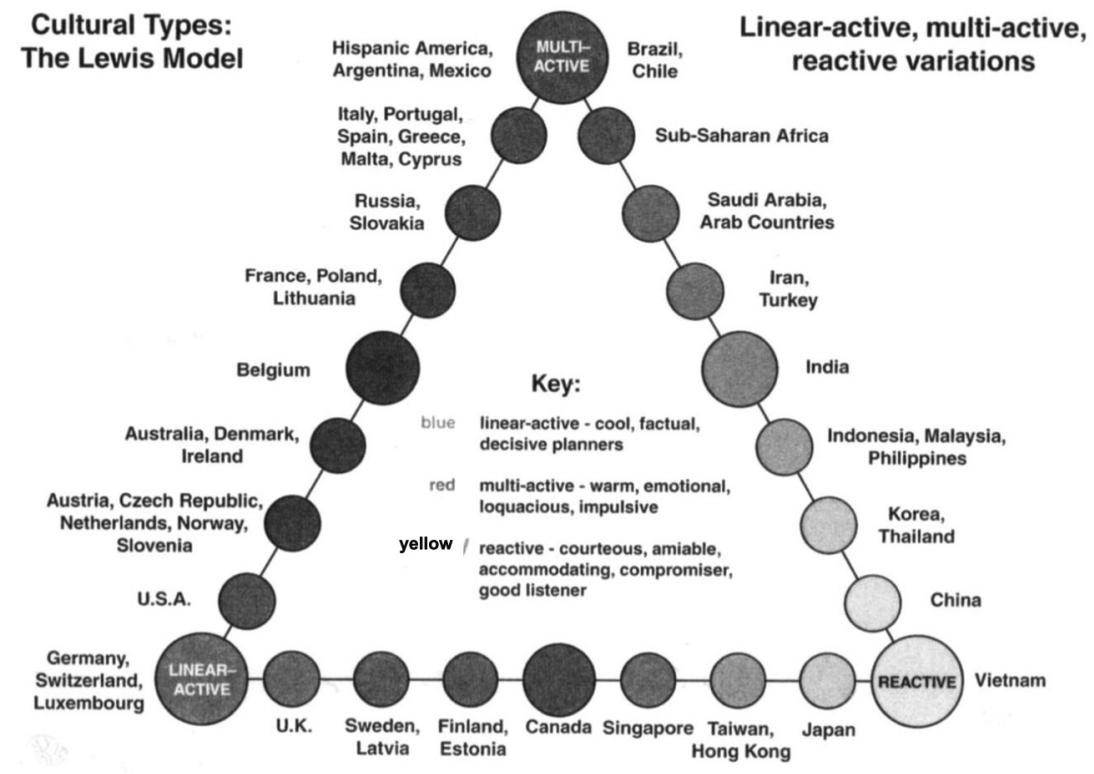

Fig. 1 LMR model by Richard Lewis [20] 
Diane Rosseau, France

\begin{tabular}{|c|c|c|}
\hline Linear-active & Multi-active & Reactive \\
\hline talks half the time & talks most of the time & listens most of the time \\
\hline plans ahead step by step & plans grand outline only & plans with general principles \\
\hline polite but direct & emotional & polite and indirect \\
\hline uses official channels & seeks out top or key person & uses connections \\
\hline partly hides feelings & shows feelings & hides feelings \\
\hline does one thing at a time & does several things at once & reacts to partners actions \\
\hline dislikes losing face & has good excuses & must not lose face \\
\hline job-oriented & people-oriented & relationship oriented \\
\hline confronts logically & confronts emotionally & never confronts \\
\hline rarely interrupts & often interrupts & does not interrupt \\
\hline puts truth before diplomacy & has a flexible truth & puts diplomacy before truth \\
\hline sometimes impatient & impatient & patient \\
\hline limited body language & unlimited body language & subtle body language \\
\hline uses mainly facts & puts feelings before facts & statements are promises \\
\hline $\begin{array}{l}\text { separates the social and } \\
\text { professional }\end{array}$ & mixes the social and professional & connects the social and professional \\
\hline
\end{tabular}

\section{L-M-R Ratina}

Fig. 2 Cultural comparisons [21]

\section{B}

A good sense of humor is an admired quality in many cultures - mainly among the British, Americans and in Latin countries even of the type of humor can vary from wordplays to sarcasm, etc. In other cultures, however - particularly Germanic ones - humor is not considered appropriate in a business context. One should not to be a comedian with the British, but always smile at their attempts at humor. With Germans or Swiss, it is better to leave the jokes for the bar after the meeting.

$\mathrm{C}$

The amount of socializing we do prior to and during a negotiation depends both on your own and the opposite team's negotiation styles and the place where the negotiation is held. In Japan, for example, the negotiation process is long and relationship/confidence building plays an important part. The same is true of the Middle East. In the USA things move faster and their negotiating style tends to be more informal and sometimes unfriendly. In Germany there may be little time for small talk. Following the opponents' lead helps, but we should do all to create rapport.

$\mathrm{D}$

Mixing with colleagues out of work-hours is an integral part of business in America where many companies are run like sports teams with the boss as captain and/or coach. Elsewhere, there may be a strong dividing line between work and home. The message is: In social situations simply be yourself, do not do anything that offends you or that may offend your hosts.

$\mathrm{E}$

Different people have different ideas about an appropriate place to do business. For some, talking about golf all morning at the office and business all afternoon on the golf course is quite normal. Others do more business in bars than boardrooms. But these days people are more culturally aware and do not usually expect for- eigners to observe their own business customs. The message to the question sounds: A polite refusal to go to a Finish sauna or Spanish bullfight will not usually offend.

In our thinking on cultural understanding we would finally like to stress and lean on the ways Silvia Schroll Machl [24] suggests for a better understanding among cultures:

Step 1 It is very necessary to get to know and get in touch with a foreign culture but as well to know and respect ones own culture, Step 2 It is crucial to be aware and respect the differences in cultures,

Step 3 It is recommended to make a step forward towards general understanding but not in a way that the participant will have to or will be forced to lose their own identity.

\section{Conclusion}

Globalization, internationalization, cooperation, new management methods and trends are interesting areas for discussion. We have to bear in mind that one should not be judging whether other ways of doing are right or wrong, but instead be aware of the differences, and not see his/her own culture and his/her way of doing as the only one which is good.

Categories such as respect, understanding, genuine interest in members of other cultures, as well as attempts to be open-minded, adaptable and sensitive towards them, are the paths to be followed. We are convinced that these principles do not apply only for "doing business abroad" but what is more they help to promote the win-win strategy in many areas of life. 


\section{References}

[1] The Economist articles referred to above appeared as a School Briefs series weekly form 18 October to 6 December, 1997, Available at [http.//www.ft.com].

[2] The Financial Times produced a series, ”The Global Company“, 1 October to 7 November, 1997; also in ten parts, "Mastering Global Business", 1998. These can be found on the FT archive at www.ft.com.

[3] GIBSON, R. (2000): Intercultural Business Communication, Oxford University Press. ISBN 0-19-442180-5.

[4] Market Leader,. (2000): Pearson Education Limited.

[5] HIRD, J. (2002): Business behavior. In: Gomm, H. (2002): In Company Intermediate. Oxford, Macmillan Publishers Limited, p. 155.

[6] HIRD, J. (2002): Business behavior. In: Gomm, H. (2002): In Company Intermediate. Oxford, Macmillan Publishers Limited, p. 159.

[7] BAKIC-MIRIC, N. (2008): Re-imaging Understanding of Intercultural Communication, Culture and Culturing. Journal of Intercultural Communication ISSN 1404-1634 issue 17, June 2008.

[8] LEWIS, D. R. (2009): When cultures collide. Leading across cultures. 3rd Edition. Boston/London, Nicolas Brealey International, ISBN 978-1-904-838-02-9. p. 154.

[9] TROMPENAARS, F., TURNER, CH. H. (1997): Riding the Waves of Culture. London, Nicholas Brealey.

[10] POWELL, M. (2002): In Company. Oxford, Macmillan Publishers Limited, p. 57.

[11] POWELL, M. (2002): In Company. Oxford, Macmillan Publishers Limited, p. 59.

[12] HALL, E. T., HOFSTEDE, G., TROMPENAARS, F., THOMAS, A., KINAST, E.U., SCHROLL-MACHL, S., NOVY etc.

[13] HALL, T. E. (1983): The Dance of Life. The Other Dimension of Time. New York, Doubleday.

[14] These points are taken from Michelle LeBaron, Bridging Cultural Conflicts: New Approaches for a Changing World (San Francisco: Jossey Bass, 2003) In: LeBARON, M. (2003) Communication Tools for Understanding Cultural Differences. Beyond Intractability. Eds. Guy Burgess and Heidi Burgess. Conflict Research Consortium, University of Colorado, Boulder. Posted: June 2003, <http://www.beyondintractability.org/essay/communication_tools/>.

[15] LeBARON, M. (2003) Communication Tools for Understanding Cultural Differences. Beyond Intractability, Eds. Guy Burgess and Heidi Burgess, Conflict Research Consortium, University of Colorado, Boulder, Posted June 2003, <http://www.beyondintractability.org/essay/communication_tools/>.

[16] Quoted in Tracy Novinger, Intercultural Communication (Austin, TX: University of Texas Press, 2001), 31. In: LeBARON, M. (2003) Communication Tools for Understanding Cultural Differences, Beyond Intractability. Eds. Guy Burgess and Heidi Burgess. Conflict Research Consortium, University of Colorado, Boulder. Posted: June 2003, <http://www.beyondintractability.org/essay/communication_tools/>.

[17] LeBARON, M. (2003) Communication Tools for Understanding Cultural Differences. Beyond Intractability. Eds. Guy Burgess and Heidi Burgess. Conflict Research Consortium, University of Colorado, Boulder. Posted: June 2003, <http://www.beyondintractability.org/essay/communication_tools/>.

[18] HOFSTEDE, G.(1984): Culture's Consequences, Sage.

[19] LEWIS, D. R. (2009): When cultures collide. Leading across cultures. 3rd Edition. Boston/London, Nicolas Brealey International, ISBN 978-1-904-838-02-9.

[20] Available at: [http://www.crossculture.com/UserFiles/Image/The_Lewis_Model_712.jpg] 2010-01-28.

[21] Available at: [http://www.crossculture.com/UserFiles/Image/LMR_660.jpg] 2010-01-28.

[22] POWELL, M. (2002): In Company. Oxford, Macmillan Publishers Limited, p. 40.

[23] POWELL, M. (2002) In Company. Oxford, Macmillan Publishers Limited, p. 124.

[24] THOMAS, A., KINAST, E., U., SCHROLL-MACHL, S. (2003): Handbuch interkultureller Kommunikation und Kooperation: Band 1: Grundlagen und Praxisfelder. 1. Auflage. Gottingen, Vandenhoeck\&Ruprecht. 